\title{
UNDERSTANDING LANGUAGE LEARNING: REVIEW OF THE APPLICATION OF THE INTERACTION MODEL IN FOREIGN LANGUAGE CONTEXTS
}

\author{
${ }^{1}$ L. Quentin Dixon \& ${ }^{2}$ Shuang Wu \\ ${ }^{1,2}$ College of Education and Human Development \\ Texas A\&M University, USA \\ 'Corresponding author:qdixon@cehd.tamu.edu
}

\begin{abstract}
Purpose - This paper examined the application of the inputinteraction-output model in English-as-Foreign-Language (EFL) learning environments with four specific questions: (1) How do the three components function in the model? (2) Does interaction in the foreign language classroom seem to be effective for foreign language acquisition? (3) What factors might facilitate/impede interaction, which, in turn, positively or negatively affect output? (4) What are effective teaching methods to enhance interaction and ensure quality of output?
\end{abstract}

Methodology - A systematic search for empirical studies was conducted in the selected databases, which yielded 26 studies from different parts of the world. These studies met the preset criteria concerning medium of instruction, setting, relevancy and quality.

Findings - The review demonstrated that when input, interaction and output worked together, positive English learning results were achieved by EFL learners. In addition, the relationship among input, interaction, and output was likely to be influenced by such factors as language environment, task type, gender, and language proficiency. The review also showed that in the face of diversified forms of interaction, EFL teachers were capable of efficiently implementing different teaching strategies.

Significance - The review not only lends support to the applicability of the interaction model in foreign language contexts, but also suggests from the pooled evidence, effective ways to apply the 
model in the EFL class. These findings can be used to help launch educational campaigns promoting the application of the interaction model within the EFL classroom.

Keywords: Input, interaction, output, EFL settings, language learning.

\section{INTRODUCTION}

Internationally, interest in studying English in foreign language contexts has grown explosively in recent years (Hu, 2007). However, these efforts to learn English often do not lead to high levels of proficiency for the students (Byun, Chun, Kim, Park, Kim \& Jung, 2011; Chen \& Goh, 2011). In some cases, it may be that educational policies and/or teacher practices do not reflect an understanding of how languages are learned. This review of the literature aims to help explain how English is learned in foreign language learning contexts via one model of language learning, the interaction model (Long, 1996).

There are many different theories or approaches to studying foreign or second language learning. VanPatten and Williams (2007) examine nine different theories of foreign or second language acquisition; the contributions of four broader approaches to foreign or second language learning are examined in Dixon et al. (2012) review. However, the model or theory we focus on in this paper is the interaction model, one of the few theories or approaches to language learning that posits an important and direct role for language instruction (Ortega, 2007).

The interaction model is mainly synthesized from two hypotheses: S. Krashen's Input Hypothesis and M. Swain's Output Hypothesis (Gass \& Mackey, 2006). However, it was Long (1996) who clearly proposed interactional negotiation of meaning (i.e., interaction) as essential for enhancing comprehensible input and yielding desirable output. Over the years, research interest has been drawn to the ways interaction connects input and output, as well as the proximal environment in which interaction increases (Gass \& Mackey, 2006). At its most basic, the interaction model views language learning as occurring during an input-output-interaction cycle (Gass \& Mackey, 2006). Input is the language which the learner encounters; output is the learner's productive language; and interaction is the means by 
which the learner can indicate comprehension or non-comprehension of the input, can directly request clarification or modification of the input, can attempt a response, and can obtain feedback on the learner's own output (Gass \& Mackey, 2006).

According to the interaction model, this interactive process by which language is acquired is termed negotiation of meaning (Gass $\&$ Selinker, 2008); that is, the two (or more) speakers together work toward a successful communication by modifying their speech or requesting the other to modify theirs. For example, in a conversation between a native speaker and a learner of the language, the native speaker may simplify her speech in order to help the learner understand (Gass, 1997). The learner may ask questions to prompt the native speaker to clarify her utterance, or the learner's response to the speaker may reveal a misunderstanding which may prompt the native speaker to try a different way to convey her meaning (Gass \& Mackey, 2006). Alternatively, as the learner produces language as a response, the learner may try different ways of expressing his meaning as he receives feedback from the native speaker that his first attempt was not understood (Gass \& Selinker, 2008). Although for ease of understanding we have just described this as a native speaker-learner interaction, learners can also engage in this process with other learners and improve their output accordingly.

Feedback is viewed by the interaction model proponents to be a crucial aspect of interaction that facilitates language learning (Gass \& Mackey, 2006). Feedback can come in many forms, such as explicit or implicit (Gass, 1997). In a foreign language learning context, explicit feedback could be offered by a teacher saying (in response to a learner saying "She goed to the store"), "No, we do not say goed in English; the proper form is went." However, a common form of implicit feedback is a recast (Gass \& Selinker, 2008); that is, the teacher (or interlocutor) re-phrases the learner's utterance using the correct form, without noting that the learner's utterance was incorrect. To use the same example as above, the teacher offering a recast would simply respond: "She went to the store," possibly with a rising question intonation.

Why is it, though, that some new vocabulary items or grammatical forms seem to be acquired after an exchange, but other items or forms are not? The interaction model emphasizes attention to new 
vocabulary or grammatical forms, often called noticing (Gass \& Selinker, 2008). A learner may understand the input, but not notice that the form, for example, differs from the learner's knowledge of the language; only with noticing can the new form possibly be integrated into the learner's knowledge and use of the language (Gass $\&$ Selinker, 2008). This noticing may be conscious or unconscious (Gass, 1997). Noticing, combined with input or feedback that offers a new form that the learner had not previously mastered, can lead to intake, or the comparison of the new form with the learner's current state of knowledge of the language (Gass \& Selinker, 2008). If the two forms are perceived to differ, integration of the new form into the learner's existing knowledge of the language may occur; however, many exposures to the new form may be required before integration is complete, or integration may fail to occur even after intake (Gass \& Selinker, 2008).

The interaction model provides a detailed account of the necessary processes for foreign language acquisition and at what points teachers may be able to intervene to facilitate the process. However, as Mackey warned, despite its wide recognition, the interaction model should not be accredited as "a complete theory of SLA (second language acquisition)" (2007, p. 30). In other words, the interaction model may not be able to explain political and cultural influences on SLA. In the long run, this model also needs breakthroughs from other theories or approaches to account for differentiated language outcomes due to personality and cognitive factors (Gass \& Mackey, 2006).

Our questions for this review of the research are: How do the three components function in the model? Does interaction in the foreign language classroom seem to be effective for foreign language acquisition? What factors might facilitate/impede interaction, which, in turn, positively or negatively affect output? What are the effective teaching methods to enhance interaction and ensure quality of output?

\section{Literature Surveyed}

The literature search for relevant studies was conducted using the following online databases: ERIC, PsycInfo, and Language and Linguistic Behavior Abstracts (LLBA). Searches were limited to the 
category of "abstract", and the period from 1995 to present. The three components of the interaction model (i.e. "input", "interaction", and "output") were crossed with "second language acquisition" "second language learning", "L2 acquisition", "L2 learning", "foreign language acquisition", and "foreign language learning".

The first round of search yielded a total of 703 articles. Then a manual screening of articles was conducted for articles that met the following criteria:

1. English was the language under investigation;

2. The study was conducted on learners who learned English as a foreign language, with focus on their formal language learning in class;

3. The studies were empirical;

4. To ensure relevancy to the model, the studies examined the role of one of the three components of the model or tested the whole model;

5. Studies must meet a standard of rigor appropriate to the research questions and methods; for example, for quantitative studies employing inferential statistics, sample size needed to be adequate; qualitative studies needed to include triangulation of data sources.

In this review paper, we will use the term "foreign language" to indicate a language being learned in a context in which students of the language encounter little need to use the foreign language in their day-to-day interactions; all regular daily activities can be accomplished through their first language (L1). The foreign language classroom is the main environment for learning the language, and the foreign language teacher is typically the most proficient speaker of the foreign language that the students regularly encounter. The foreign language context contrasts with what is often termed a "second language" context, in which learners, typically immigrants, are living in a society in which the language to be learned is the main language. Because the second language environment generally offers more opportunities for interaction between learners and native speakers of the language than the foreign language environment, we chose to limit our study to the explanatory power and application of the interaction model to language learning in foreign language contexts. 


\section{RESULTS}

The resulting 26 studies selected were researches conducted in different parts of the world: one in South America (country unspecified), 19 in Asia (China, Iran, Japan, Korea, Malaysia, Thailand), five in Europe (Germany, Israel, Netherlands, Spain) and one in Africa (Zaire). The findings are organized around the four research questions as follows:

\section{Operational Process of the Interaction Model}

Like the three legs of a triangle, input, interaction and output make a strong model. With the absence of any one of these three components "input", "interaction" and "output", learners may experience a slowdown in their language development. For example, continuous input, if ignored by learners, might fail to yield any noticeable results, as in the case study of an upper-intermediate level Japanese college student (Nabei \& Swain, 2002). Nabei and Swain (2002) found that the teacher's recasts in teacher-student interaction were not necessarily translated into the student's immediate learning of English, as the student either failed to notice the occurrence of the recast, or did not understand why the recasts had been given.

Conversely, when the three components are in place, EFL learners are most likely to improve their language skills (Ding, 2007; House, 1996). In Ding's study (2007), three Chinese learners attributed their success (winning prizes in nationwide English speaking competitions and debate tournaments) to text memorization and imitation. Although at first this method seemed irrelevant to interaction, reciting and imitating audio-recordings of texts and speeches actually helped these students notice the productive use of language and learn pronunciation. More crucially, their teachers also listened to their recitation attempts and provided feedback, which offered them opportunities to notice differences in pronunciation or grammar that they had missed during their selfpractice. Similarly, German students also managed to expand their repertoire of pragmatic strategies when they were given explicit instruction and engaged in self-reflection on their own output (House, 1996). 


\section{Effectiveness of the Application of the Interaction Model}

Interaction can take place between peers, teachers and students, even between students and specially-designed teaching software. In fact, with technology making its way into modern language teaching approaches, it is no longer unusual that multimodal interaction is currently practiced in EFL classrooms. Overall, the review showed that interaction in varying forms could enhance language output.

Peer Interaction. Collaboration among peers can help EFL learners pool their linguistic and cultural resources in order to ensure desirable language output. For example, in one study (Sundrarajun \& Kiely, 2010), when the Thai learners were grouped for discussion followed by oral presentations, the group members indeed collaborated with each other and gave better presentations in terms of manifesting more cohesive texts, richer information, and improved lexical features.

Student-teacher Interaction. Teachers' feedback in combination with new opportunities for language practice can help improve students' language development. When investigating the combined effects of negative feedback and modified output opportunities, McDonough (2005) found that the Thai learners of English made improvement in English question development when they were allowed to modify their own output after receiving negative feedback from the native English-speaking lecturers. Even delayed interaction could still encourage learners' vocabulary use and promote their incidental acquisition of words. When nine South American university students interacted with one native-speaker teacher (who gave comments instead of corrections after the students submitted their journals) via both oral and written dialogue journals, these students seemed to acquire vocabulary incidentally, gradually applying their new vocabulary knowledge in their journals (Brown, Sagers \& LaPorte, 1999). However, Brown et al.'s study only involved advanced learners; therefore, it still needs further validation to determine whether beginners or low-proficient learners could benefit from this type of interaction.

Computer-assisted Multimodal Interaction. Computer-assisted learning via software, emailing, texting and online chatting is gaining in popularity in EFL classrooms. However, despite the increasingly 
important role of modern technology in language learning, the majority of the studies tend to suggest that the combination of technology-assisted interaction and traditional human interaction can enable richer and more effective interaction for learners with different levels of language proficiency.

Overall, EFL students can improve their reading comprehension and writing skills when they are engaged in computer-assisted peer interaction. In a study of 267 first-year university EFL majors in Japan, Murphy (2010) found that by enabling the students to selfcheck their mistakes and exchange ideas between partners, computerassisted elaborative feedback helped the students sharpen their reading skills, and produce more quality interaction between pairs. In addition, in another study concerning the impact of multimodal interaction on reading, Murphy (2007) came to the conclusion that the students performed better in pairs than individually when provided with technology-assisted elaborative feedback. Pair work assisted with computer technology also played positive roles in learners' writing, a finding further supported by Liaw's study (1998). Over time, the randomly-paired email pals reported progress in their speed of writing and in revision skills of writing, as well as increased motivation and interest in learning English (Liaw, 1998). However, in comparison to Murphy's two studies, Liaw's (1998) findings have weaker generalizability, due to the much smaller sample size and its lack of formal assessment.

In computer-assisted multimodal interaction, even low-proficiency learners could have lots of opportunities to prompt negotiation and noticing, as in face-to-face interaction (Tam, Kan, \& $\mathrm{Ng}$, 2010). However, in the computer environment, despite the gains in negotiating for comprehensible input, the low-proficiency learners might still have problems in producing comprehensible input (Tam et al., 2010). As the Tam et al. (2010) study did not monitor the students' language development longitudinally via multimodal interaction, no definite conclusion could be drawn concerning whether multimodal interaction was beneficial for all EFL learners regardless of their proficiency levels.

\section{Factors Impacting Interaction}

The interaction-oriented studies in EFL settings reflect the researchers' interest in discovering what individual and social 
factors might influence interaction types and patterns, rather than in challenging/defending the positive role of interaction in language learning. Based on the studies, factors impacting interaction ranged from language environment to gender traits. Though several studies even attempted to investigate more than one factor, no direct comparison was ever made to conclude which factor might be a stronger variable.

Language Environment. As English is not used for social communication on a daily basis in EFL settings, most EFL learners have limited access to authentic interaction or high-quality interaction. To make matters worse, these EFL learners may be totally unaware of the role of interaction in facilitating their English proficiency. By combining cluster sampling and random sampling, $\mathrm{Wu}$ and $\mathrm{Wu}$ (2008) examined 593 Taiwan freshman students' perception of their EFL learning environment: school infrastructure, instruction, and class/school/community interaction. The results showed that the majority of students considered their EFL learning environment as learner-unfriendly. In addition, in terms of promoting English proficiency, these students tended to believe that factors such as school infrastructure and class instruction were far more important than class/school/community interaction. However, as the sample was drawn from only one university in Taiwan, it is questionable whether the students' perceptions of their particular EFL environment are representative of the situation in Taiwan as a whole.

English Language Proficiency. The level of English language proficiency seems to be in a positive relationship with the degree of interaction, regardless of whether the interlocutors are in the same- or mixed-proficiency groups. Chiang (2005) paired students by English proficiency to examine the possible impact of English proficiency on their interaction behaviors. The students in high-proficiency groups showed more confidence, and therefore, made more successful attempts at meaning clarification, comprehension check and gap filling. Conversely, the interaction in low-proficiency groups was frequently interrupted by the students' limited vocabulary, which led to a heavy reliance on conversations conducted in Chinese (L1). Kasanga (1996) also reported the edge that students of high proficiency had in facilitating interaction. In Kasanga's study in 
which students of high/low English proficiency were mixed in each group, students of high proficiency demonstrated frequent use of interactional strategies (e.g., elaboration, self-repair) so as to make their speech more accessible to the less competent partners. Similarly, in synchronous online chats, the more advanced learners actively assisted their less advanced peers in noticing and acquisition of forms, vocabulary, and spelling (Shekaary \& Tahririan, 2006).

Task Type. Although only two studies addressed the effects of task type, it appears the nature and objectives of tasks may influence students' amount of interaction and focus during interaction. For example, tasks requiring information and opinion exchange between learners, such as the one that allowed each participant to hold one different piece of the puzzle, tended to generate more interaction than other tasks (Kasanga, 1996). In addition, a written task following an oral discussion may help students focus more on linguistic form. In Birjandi and Tabatabaei's study (2009), 40 Iranian English teaching majors participated in three tasks: two were oral tasks and one involved group discussion followed by individual writing. With the task requiring writing, the students had more discussion about linguistic forms in this task than the other two orally-oriented tasks.

Gender. Interaction styles, which ultimately influence language output, seem to be influenced by gender, as revealed by three studies concerning gender effects on university students' interaction behaviors in Iran (Birjandi \& Tabatabaei, 2009), Japan (O'Sullivan, 2002), and Taiwan (Liaw, 1998). In Iran, where boys and girls are typically taught separately from a young age in schools, the EFL learners were more likely to become engaged in scaffolding conversations when paired with interlocutors of the same gender (Birjandi \& Tabatabaei, 2009).

The impact of gender may also be mediated by acquaintanceship between interlocutors. For example, gender in combination with acquaintanceship was found to affect linguistic accuracy rather than linguistic complexity for Japanese students (O'Sullivan, 2002). The Japanese female students made the most grammatical mistakes when paired with strangers of the opposite gender. By contrast, university students in Taiwan, who were randomly paired with strangers in email correspondence, tended to make more effort in maintaining 
two-way communication with pen pals of the opposite gender (Liaw, 1998). However, Liaw did not formally assess students' accuracy or complexity of writing. These apparently conflicting findings in the two studies may also be due to the different task types (formal assessment for the Japanese students vs. unsupervised email correspondence for the Taiwan students), or cultural differences in expectations for cross-gender interaction.

\section{Effective Teaching/Learning Strategies}

The investigation into the effectiveness of various teaching/ learning strategies turns out to be the focus of many of the reviewed studies in EFL settings. Ideally, teachers in EFL classrooms should act as language facilitators who adjust their pace and nature of input when necessary (Lee, 2003; Seong, 2009). This was also the point made by de Graaff, Koopman, Anikina, and Westhoff (2007), who strongly urged EFL teachers to adopt various strategies to facilitate exposure to input, form- and meaning-focused processing, and output production.

Input-based vs. Output-based Instruction. By comparing the effects of processing instruction and dictogloss tasks on the acquisition of the English passive voice, Qin (2008) found that input-based instruction (processing instruction) and output-based instruction (dictogloss tasks) ended up with the same results after one month. However, Song and Suh (2008) reported a different result: participants with more opportunities to produce output performed better on the production post-test. The conflicting results between these two studies might be explained by the different proficiency levels or age groups of the participants: Qin's study investigated Grade 7 beginning EFL learners in China, whereas Song and Suh's study was conducted with university-age intermediate Korean EFL learners. Opportunities for output may become more important as learners increase their proficiency, or different learning mechanisms at different ages might influence the effectiveness of certain teaching methods.

Explicit Instruction and Pre-task Planning. Students generally benefit from explicit instruction and pre-task planning. Explicit metalinguistic instruction directing students to the differences 
between L1 and L2 proved efficient in improving learners' level of English language production (Kupferberg, 1999). With strategy training programs, students were better prepared for participation in negotiation moves (Naughton, 2006). In addition, with pre-task planning, learners learned to focus not only on vocabulary, but also on morphosyntax (Park, 2010).

Other teaching strategies were also employed to heighten students' awareness of noticing and to promote interaction. For example, the use of L1 in English interaction not only eased the learners' language anxiety but also promoted positive L1-L2 transfer (Paramasivam, 2009). It was also found that poetry reading could inspire the readers to notice linguistic norms and density of meaning, helping them gradually become conscious learners (Hanauer, 2001).

\section{CONCLUSION}

To sum up, the input-interaction-output model works best when each of the three components is utilized and connected. Based on the studies, the teaching based on the interaction model was found to exert noticeably positive impact on English learning in EFL settings. In addition, the relationship between input, interaction, and output may be influenced by factors such as gender and language proficiency. How to optimize this relationship poses challenges for EFL teachers. Of the teaching strategies implemented in class, explicit instruction, pre-task planning, and input-/output-based instruction were found to be effective for EFL learners.

Despite the difficulties involved in providing opportunities for interaction within the foreign language context, this review of the literature suggests that it is possible for foreign language teachers to implement effective teaching methods by using the inputinteraction-output model. Foreign language teachers thus should work to improve their students' opportunities for interaction within and beyond the classroom.

First, within the classroom, teachers should attend to the issue of task type when assigning interactive tasks for language learning. Teachers may also want to consider the gender of paired students, 
looking to local research (or action research in their own classroom) to determine whether same gender or different gender partners will interact more. In addition, teachers should be aware that students with higher proficiency may interact more and show more confidence in interactive activities than lower-proficiency students; this suggests teachers may want to scaffold beginner students through activities with greater amounts of interaction as the students' proficiency, and confidence, increases. In addition, teachers can provide explicit instruction in forms to be acquired and strategies to be used prior to interaction and offer opportunities for pre-task planning.

Second, as far as language learning outside the classroom is concerned, teachers, as well as students, should also keep in mind that interaction does not need to be traditional face-to-face oral interaction. Interaction can be written, through journals, online chats, and email exchanges. In addition to a human, a computer may also provide feedback to promote language learning. Such awareness of diverse possibilities for interaction could motivate students to gain access to authentic interaction in natural settings, thus enhancing their language learning outcomes.

The number of eligible studies in this review might be bigger, if the literature search was not limited to the keywords in the abstracts, or to just three databases (ERIC, PsycInfo, and LLBA). Moreover, it can be reasonably assumed that with more studies synthesized, the generalizability of the findings could be strengthened.

By examining all the studies in the review, several common limitations were revealed. First, the participants of the studies should be more diversified. In the 26 studies selected, the majority of the participants were EFL university students; and the interaction predominantly took place between classmates, or other EFL peers. In fact, it would be interesting to observe how younger children may interact and benefit from the interaction model. Pairing EFL learners with native speakers and/or learners from a different first language background may also elicit more authentic interaction, as the two interlocutors could not rely on a shared first language to help convey meaning. Second, the sample sizes of the quantitative studies were mostly quite small, around 40. Though it indeed took time to observe and analyse students' interaction and measure 
their language development, the small sample sizes helped little in validating the generalizability of the findings. Third, the contexts of all the studies were mostly class activities or foreign language learning environments with formal assessments. As more English-language media are accessible in EFL settings, examination of EFL learners' interaction and output in natural settings can be a welcome addition to the research on the interaction model. Fourth, the overall design of the studies needs improving. Random sampling and longitudinal designs can greatly improve the validation of the findings.

\section{REFERENCES}

Birjandi, P., \& Tabatabaei, O. (2009). The impact of gender on the incidence and quality of form-focused episodes in task-based conversational feedback among EFL learners. The Asian EFL Journal Quarterly, 11(4), 115-147.

Brown, C., Sagers, S. L., \& LaPorte, C. (1999). Incidental vocabulary acquisition from oral and written dialogue journals. Studies of Second Language Acquisition, 21, 259-283.

Byun, K. Y., Chu, H. J., Kim, M. J., Park, I., Kim, S. H., \& Jung, J. Y. (2011). English-medium teaching in Korean higher education: Policy debates and reality. Higher Education, 62, 431-449.

Chen, Z., \& Goh, C. (2011). Teaching oral English in higher education: Challenges to EFL teachers. Teaching in Higher Education, 16, 333-345.

Chiang, M-H. (2005). Interactions in small-group, communicationoriented, freshman English classes. Journal of Pan-Pacific Association of Applied Linguistics, 9, 59-77.

de Graaff, R., Koopman, G. J., Anikina, Y., \& Westhoff, G. (2007). An observation tool for effective L2 pedagogy in content and Language Integrated Learning (CLIL). International Journal of Bilingual Education and Bilingualism, 10, 603-624.

Ding, Y. (2007). Text memorization and imitation: The practices of successful Chinese learners of English. System, 35, 271-280.

Dixon, L. Q., Zhao, J., Shin, J.-Y., Wu, S., Su, J.-H., BurgessBrigham, R., Gezer, M. U., \& Snow, C. (2012). What we know about second language acquisition: A synthesis from four perspectives. Review of Educational Research, 82, 5-60. 
Gass, S. M. (1997). Input, interaction, and the second language learner. Mahwah, NJ: Lawrence Erlbaum.

Gass, S., \& Mackey, A. (2006). Input, interaction and output: An overview. AILA Review, 19, 3-17.

Gass, S. M., \& Selinker, L. (2008). Second language acquisition: An introductory course (3rd ed.). New York, NY: Routledge.

Hanauer, D. I. (2001). The task of poetry reading and second language learning. Applied Linguistics, 22, 295-323.

House, J. (1996). Developing pragmatic fluency in English as a foreign language. SSLA, 18, 225-252.

$\mathrm{Hu}, \mathrm{G}$. W. (2007). The juggernaut of Chinese-English bilingual education. In A. Feng (Ed.), Bilingual education in China: Practices, policies and concepts (pp. 94-126). Clevedon, U.K.: Multilingual Matters.

Kasanga, L. A. (1996). Peer interaction and L2 learning. Canadian Modern Language Review, 52, 611-639.

Kupferberg, I. (1999). The cognitive turn of contrastive analysis. Language Awareness, 8(3-4), 210-222.

Lee, E. (2003). Learning through scaffolded assistance during interaction. Journal of Pan-Pacific Association of Applied Linguistics, 7(2), 189-213.

Liaw, M.-L. (1998). Using electronic mail for English as Foreign Language instruction. System, 26, 335-351.

Long, M. H. (1996). The role of the linguistic environment in second language acquisition. In W. C. Ritchie \& T. K. Bhatia (Eds.), Handbook of second language acquisition (pp. 413-468). San Diego, CA: Academic Press.

Mackey, A. (2007) (Ed.). Conversational interaction and second language acquisition: A collection of empirical studies. Oxford, U.K.: Oxford University Press.

McDonough, K. (2005). Identifying the impact of negative feedback and learners' responses on ESL question development. SSLA, 27, 79-103.

Murphy, P. (2007). Reading comprehension exercises online: The effects of feedback, proficiency and interaction. Language Learning \& Technology, 11, 107-129.

Murphy, P. (2010). Web-based collaborative reading exercises for learners in remote locations: the effects of computermediated feedback and interaction via computer-mediated communication. ReCALL, 22(2), 112-134. 
Nabei, T., \& Swain, M. (2002). Learner awareness of recasts in classroom interaction: A case study of an adult EFL student's second language learning. Learning, Language Awareness, 11, 43-63.

Naughton, D. (2006). Cooperative strategy training and oral interaction: Enhancing small group communication in the language classroom. The Modern Language Journal, 90, $169-184$.

Ortega, L. (2007). Second language learning explained? SLA across nine contemporary theories. In B. VanPatten \& J. Williams (Eds.), Theories in second language acquisition: An introduction (pp. 225-250). Mahwah, NJ: Lawrence Erlbaum Associates.

O'Sullivan, B. (2002). Learner acquaintanceship and oral proficiency test pair-task performance. Language Testing, 17(2), 109-126.

Paramasivam, S. (2009). Language transfer as a communication strategy and a language learning strategy in a Malaysian ESL classroom. The Asian EFL Journal Quarterly, 11, 192-229.

Park, S. (2010). The influence of pretask instructions and pretask planning on focus on form during Korean EFL task-based interaction. Language Teaching Research, 14, 9-26.

Qin, J. (2008). The effect of processing instruction and dictogloss tasks on acquisition of the English passive voice. Language Teaching Research, 12, 61-82.

Seong, M-H. (2009). Strategies making language features noticeable in English language teaching. Journal of Pan-Pacific Association of Applied Linguistics, 13, 113-126.

Shekaary, M., \& Tahririan, M. H. (2006). Negotiation of meaning and noticing in text-based online chat. The Modern Language Journal, 90, 557-573.

Song, M-J., \& Suh, B-R. (2008). The effects of output task types on noticing and learning of the English past counterfactual conditional. System, 36, 295-312.

Sundrarajun, C., \& Kiely, R. (2010). The oral presentation as a context for learning and assessment. Innovation in Language Learning and Teaching, 4(2), 101-117.

Tam, S. S., Kan., N. H., \& Ng, L. L. (2010). Low proficiency learners in synchronous computer- assisted and face-to-face interactions. The Turkish Online Journal of Educational Technology, 9(3), 61-75. 
VanPatten, B., \& Williams, J. (2007). Theories in second language acquisition: An introduction. Mahwah, NJ: Lawrence Erlbaum.

Wu, W-C. V., \& Wu, P. N. (2008). Creating an authentic EFL learning environment to enhance student motivation to study English. Asian EFL Journal, 10(4), 211-226. 